Journal of Mathematics and Statistics 4 (1): 9-14, 2008

ISSN 1549-3644

(C) 2008 Science Publications

\title{
Maximum Principles for Second Order Elliptic Equations in Nondivergence Form and Applications
}

\author{
Mohammad Al-Mahameed \\ Department of Mathematics, Irbid National University, \\ P.O. Box 2600, Irbid 21110, Jordan
}

\begin{abstract}
The main objectives of this study were to introduce a maximum principle for second order elliptic equations in nondivergence form and to use a nondivergence technique called the ABP method to establish the maximum principles in small domains. The advantage of this work was that we obtain a maximum principle for equations with discontinuous coefficients of the leading terms and the ABP estimate was a bound for solutions of uniformly elliptic equations written in nondivergence form with measurable coefficients. It was an essential tool in the regularity theory for fully nonlinear equations.
\end{abstract}

Key words: Maximum principles, elliptic partial differential equations

\section{INTRODUCTION}

The great usefulness of a priori bounds for solutions of second order elliptic partial differential equations is well $\mathrm{known}^{[1,8]}$. Maximum principles are particular priori bounds. We introduce a maximum principle for second order elliptic equations in nondivergence form when the coefficients of the leading terms are discontinuous ${ }^{[5,7,10]}$, then we describe in detail a nondivergence technique called the ABP method. It was introduced by Alexandroff in the sixties to study the curvature of manifolds and the solutions of elliptic equations. We use the ABP method to develop the maximum principles established by Berestycki and Nirenberg ${ }^{[12]}$ near 1991.

The ABP estimate also plays a crucial role in the Krylov and Safonov theory from 1979, which established the Harnack inequality for linear uniformly elliptic equations with measurable coefficients, written in nondivergence form. This important result allowed the development of a regularity theory for fully nonlinear equations.

\section{MATERIALS AND METHODS}

Let $\Omega$ be a domain (bounded connected open set) of $\mathrm{R}^{\mathrm{n}}$ we consider the Dirichlet problem

$$
\sum_{i, j=1}^{n} a_{i j}(x) \frac{\partial^{2} u}{\partial x_{i} \partial x_{j}}=f,\left.u\right|_{\partial \Omega}=0
$$

Where the following conditions are fulfilled by the coefficients and the known term,

$$
\begin{gathered}
\mathrm{a}_{\mathrm{ij}}(\mathrm{x}) \in \mathrm{L}^{\infty}(\Omega) \\
\mathrm{a}_{\mathrm{ij}}(\mathrm{n})=\mathrm{a}_{\mathrm{ji}}(\mathrm{n}) \\
\lambda|\xi|^{2} \leq \sum_{\mathrm{i}, \mathrm{j}=1}^{\mathrm{n}} \mathrm{a}_{\mathrm{ij}} \xi_{\mathrm{i}} \xi_{\mathrm{j}} \leq \beta|\xi|^{2}, \mathrm{f} \in \mathrm{L}^{2}(\Omega)
\end{gathered}
$$

with $\lambda, \beta$ positive constants. We look for

$$
\mathrm{u} \in \mathrm{W}^{2, \mathrm{n}}(\Omega) \cap \mathrm{C}^{0}(\bar{\Omega})\left(=\mathrm{W}^{2, \mathrm{n}}(\Omega)\right.
$$

if $\Omega$ is regular) and (1) is verified a.e. A current classical result of Alexandrov, Pucci and Talenti ${ }^{[1,8]}$ states that

Theorem 1: If $\mathrm{f} \in \mathrm{L}^{\mathrm{n}}(\Omega)$, then any solution of (1) the following bound (maximum principle) holds,

$$
\|\mathrm{u}\|_{L^{\infty}(\Omega)} \leq \mathrm{K}\|\mathrm{f}\|_{L^{\mathrm{n}}(\Omega)}
$$

Where $\mathrm{K}$ is a positive constant depending only on $\lambda, \beta, \Omega, \mathrm{n}$.

In theorem $1, f \in \mathrm{L}^{\mathrm{n}}(\Omega)$, where $\mathrm{n}$ is the dimension of the space is fundamental. Nevertheless in many cases obtaining bounds like (3) with some power p less than $n$ can be useful.

In this study we construct a physical case in which the hypothesis $\mathrm{p}<\mathrm{n}$ is interesting. Then we state a result like Theorem 1 for $\mathrm{p}<\mathrm{n}^{[3,5]}$ and prove a bound for this $\mathrm{p}$ (when $\lambda \rightarrow 0^{+}$). Let $n=2$. We derive the equation from 
the displacement of a structure covering $\Omega$ and clamped on $\partial \Omega$.

The structure is a net of steel cables with rectangular mesh with edges parallel to the coordinate axes. The draught of the net can be realized with turnbuckles or with weights and is assigned. The cables parallel to the $y$-axes are stretched by a draught $a_{1}=a_{1}(x)$ that we can suppose is defined in the first projection of $\Omega, \Omega_{1}$ and belongs to $L^{\infty}\left(\Omega_{1}\right)$, in general continuous a.e or a step function. Analogously the cables parallel to the x-axes are stretched by a draught $\mathrm{a}_{2}=\mathrm{a}_{2}(\mathrm{y})$ belonging to $\mathrm{L}^{\infty}\left(\Omega_{2}\right)$, where $\Omega_{2}$ is the second projection.

The structure must support a load $\mathrm{f}_{1}(\mathrm{x}, \mathrm{y})$ given by the sum of the dead load and of an accidental load like wind pressure or weight of snow and a load $f_{2}(x, y)$ given by some assigned, distributed, or concentrated loads.

We emphasize here that in the case of concentrated loads it is very natural to expect $f_{2}(x, y)$, like $1 /(\mathrm{d}(\mathrm{p}, \overline{\mathrm{p}}))^{\sigma}$ where $\overline{\mathrm{p}}(\overline{\mathrm{x}}, \overline{\mathrm{y}})$ is a fixed point in $\bar{\Omega}, \mathrm{d}(\mathrm{p}, \overline{\mathrm{p}})$ is the Euclidean distance from $\mathrm{p}(\mathrm{x}, \mathrm{y})$ to $\overline{\mathrm{p}}$ and $\sigma$ is a positive constant depending on the load.

In this case, easily arising from the applications,

$$
\mathrm{f}(\mathrm{x}, \mathrm{y})=\mathrm{f}_{1}(\mathrm{x}, \mathrm{y})+\mathrm{f}_{2}(\mathrm{x}, \mathrm{y})
$$

does not belong to $\mathrm{L}^{\mathrm{n}}(\Omega)$, for any $\sigma \geq 1$.

We call $\mathrm{u}(\mathrm{x}, \mathrm{y})$ the displacements along the z-axes orthogonal to the plane of $\Omega$. The equation that we derive expresses the balance in the vertical translation of the element dxdy of $\Omega$.

We consider displacements belonging to $\mathrm{C}^{2}(\Omega) \cap \mathrm{C}^{0}(\bar{\Omega})$ and call $\mathrm{C}_{\mathrm{x}}$ the intersection of the graph of $\mathrm{u}$ restricted to dxdy with the plane $\mathrm{y}, \mathrm{z}$. If $\mathrm{dx}$ is small we can suppose that the angle $\alpha$ formed by the tangent in $\mathrm{dx}$ to $\mathrm{C}_{\mathrm{x}}$ and the $\mathrm{y}$-axes is constant. Then the contribution of $a_{1}(x)$ to the balance is

$$
d a_{1}=-a_{1} \sin \alpha d x+a_{1} \sin \left(\alpha+\frac{d \alpha}{d y} d y\right) d x
$$

We use the small displacement hypothesis ${ }^{[6]}$ and then we can replace $\alpha$ with $\sin \alpha$ or with $t_{g \alpha}$, from which

$$
\mathrm{da}_{1}=-\mathrm{a}_{1} \alpha \mathrm{dx}+\mathrm{a}_{1}(\alpha+\mathrm{d} \alpha) \mathrm{dx}=\mathrm{a}_{1} \frac{\mathrm{d} \alpha}{\mathrm{dx}} \mathrm{dydx}
$$

Otherwise $\mathrm{t}_{\mathrm{g} \alpha}=\frac{\partial \mathrm{u}}{\partial \mathrm{y}}$ and then

$$
\mathrm{da}_{1}=\mathrm{a}_{1} \frac{\partial^{2} \mathrm{u}}{\partial \mathrm{y}^{2}} \mathrm{dydx}
$$

Analogously, on the edges parallel to the y-axes the contribution of $a_{2}(y)$ to the balance is

$$
\mathrm{da}_{2}=\mathrm{a}_{2} \frac{\partial^{2} \mathrm{u}}{\partial \mathrm{x}^{2}} \mathrm{dxdy}
$$

To obtain the balance, the sum of $f(x, y) d x d y$, (4) and (5) must be zero. We deduce

$$
f d x d y+a_{1} \frac{\partial^{2} u}{\partial y^{2}} d y d x+a_{2} \frac{\partial^{2} u}{\partial x^{2}} d x d y=0
$$

and then

$$
\mathrm{a}_{1}(\mathrm{x}) \frac{\partial^{2} \mathrm{u}}{\partial \mathrm{y}^{2}}+\mathrm{a}_{2}(\mathrm{y}) \frac{\partial^{2} \mathrm{u}}{\partial \mathrm{x}^{2}}=\mathrm{f}(\mathrm{x}, \mathrm{y})
$$

Equation (6) is of type (1) but $\mathrm{f}(\mathrm{x}, \mathrm{y})$ in many cases does not belong to $\mathrm{L}^{\mathrm{n}}(\Omega)$, as we have pointed out. Then we are interested in the case in which (3) holds with some power less than $\mathrm{n}$ in the right member.

\section{THE RESULTS}

In this section we first deduce some results concerning the estimate (in $\mathrm{L}^{\infty}$ norm) of the displacement of a structure when the load is function $\mathrm{f}$ not belonging to $\mathrm{L}^{\mathrm{n}}(\Omega)$, e.g., the inverse of a distance from an assigned point of $\bar{\Omega}$. We return to (1) with hypotheses (2). In a first step we suppose

$$
\mathrm{a}_{\mathrm{ij}}(\mathrm{x}) \in \mathrm{C}^{\infty}(\Omega) ; \sum_{\mathrm{i}=1}^{\mathrm{n}} \mathrm{a}_{\mathrm{ii}}(\mathrm{x})=1
$$

Related to the operator

$$
\mathrm{Lu}=\sum_{\mathrm{i}, \mathrm{j}=1}^{\mathrm{n}} \mathrm{a}_{\mathrm{ij}}(\mathrm{x})\left(\partial^{2} \mathrm{u} / \partial \mathrm{x}_{\mathrm{i}} \partial \mathrm{x}_{\mathrm{j}}\right)
$$

we consider its adjoint operator

$$
L^{*} v=\sum_{i, j=1}^{n}\left(\partial^{2} / \partial x_{i} \partial x_{j}\right)\left(a_{i j} v\right)
$$


A function $\mathrm{v}$ belonging to $\mathrm{L}_{\text {loc }}^{1}(\Omega)$ is a nonnegative weak solution of $\mathrm{L}^{*} \mathrm{v}=0$ if $\mathrm{v} \geq 0$ $\int_{\Omega} \mathrm{vLu}=0$ for all $\mathrm{u} \geq 0, \mathrm{u} \in \mathrm{C}_{0}{ }^{\infty}(\Omega)$.

The following theorem is crucial for our considerations. Let $\mathrm{v}$ be a nonnegative weak solution of $L^{*} v=0$.

Theorem 2: For any $\lambda \in(0,1 / \mathrm{n}]$ there exists $\delta>0, \delta=\delta(\lambda)$, such that

$$
\int_{\mathrm{B}_{\mathrm{r}}} \mathrm{v}(\mathrm{y}) \mathrm{dy} \leq \frac{\mathrm{c}}{\lambda} \int_{\mathrm{B}_{(1-\delta) \mathrm{r}}} \mathrm{v}(\mathrm{y}) \mathrm{dy}
$$

With $\mathrm{c}=\mathrm{c}(\mathrm{n})$, for any ball $\mathrm{B}_{\mathrm{r}}$ such that $\mathrm{B}_{(1+2 \delta) \mathrm{r}} \subset \Omega$. Here $\mathrm{B}_{\mathrm{r}}, \mathrm{B}_{(1+2 \delta) \mathrm{e}}, \mathrm{B}_{(1-\delta) \mathrm{r}}$ are concentric balls with radii $r,(1+2 \delta) r,(1-\delta) r$. Moreover there exists a positive constant $K$ such that $\lambda / \delta \leq K$, for any $\lambda \in(0,1 / \mathrm{n}]$.

Proof: From now on we denote with $\mathrm{c}$ a generic positive constant depending only on $\mathrm{n}$ and suppose that $\mathrm{B}_{\mathrm{r}}$ is centered at the origin. Fix $0<\delta<1$. There exists $\mathrm{g} \in \mathrm{C}_{0}^{\infty}\left(\mathrm{B}_{(1+28)_{\mathrm{r}}}\right)$ such that

$$
\begin{gathered}
\mathrm{Lg} \geq 0 \text { in } \mathrm{B}_{(1+\delta) \mathrm{r}}-\mathrm{B}_{(1-\delta) \mathrm{r}} \\
\mathrm{Lg}>\mathrm{k}_{1} \text { in } \mathrm{B}_{\mathrm{r}}-\mathrm{B}_{(1-\delta) \mathrm{r}},|\mathrm{Lg}| \leq \mathrm{k}_{2} \text { in } \Omega
\end{gathered}
$$

for some positive constants $\mathrm{k}_{1}, \mathrm{k}_{2}$ depending on $\mathrm{g}$.

As $\mathrm{g}$ depends on $\delta$ we obtain $\mathrm{K}_{1}=\lambda \mathrm{c}_{1}(\delta), \mathrm{k}_{2}=\mathrm{k}_{2}(\delta)$. If we choose $\delta=\delta(\lambda)$ it is easy to verify that we can pick $\delta$ such that

$$
\frac{\mathrm{k}_{2}(\delta)}{\mathrm{c}_{1}(\delta)} \leq \mathrm{c}, \frac{\lambda}{\delta} \leq \mathrm{c}
$$

for $\lambda \in(0,1 / \mathrm{n}]$

For example, we can choose

$$
\delta=(\sqrt{1+2 \lambda}-1) /(2(\sqrt{1+2 \lambda}+1))
$$

and

$$
\mathrm{g}(\mathrm{x})=\left[(1+\delta)^{2} \mathrm{r}^{2}-|\mathrm{x}|^{2}\right]^{2}
$$
deduce

From (8), as $\mathrm{v}$ is a nonnegative weak solution we

$$
\begin{gathered}
\int_{\mathrm{B}_{\mathrm{r}}-\mathrm{B}_{(1-\delta) \mathrm{r}}} \mathrm{v}(\mathrm{y}) \mathrm{dy}=\frac{1}{\mathrm{k}_{1}} \int_{\mathrm{B}_{\mathrm{r}}-\mathrm{B}_{(1-\delta) \mathrm{r}}} \mathrm{v}(\mathrm{y}) \mathrm{Lg}(\mathrm{y}) \mathrm{dy} \\
\leq \frac{1}{\mathrm{k}_{1}} \int_{\mathrm{B}_{(1+\mathrm{v}) \mathrm{r}}-\mathrm{B}_{(1-\delta) \mathrm{r}}} \mathrm{v}(\mathrm{y}) \mathrm{Lg}(\mathrm{y}) \mathrm{dy} \leq \frac{\mathrm{k}_{2}}{\mathrm{k}_{1}} \int_{\mathrm{B}_{(1-\delta) \mathrm{r}}} \mathrm{v}(\mathrm{y}) \mathrm{dy}
\end{gathered}
$$

from which, using (9),

$$
\int_{\mathrm{B}_{\mathrm{r}}} \mathrm{v}(\mathrm{y}) \mathrm{dy} \leq \frac{\mathrm{c}}{\lambda} \int_{\mathrm{B}_{(1-\delta) \mathrm{r}}} \mathrm{v}(\mathrm{y}) \mathrm{dy}
$$

and the theorem is proved.

From theorem 2, using the same arguments as those of ${ }^{[3,5]}$ and the well known Gehring theorem ${ }^{[4,9,11]}$ it is easy to deduce the estimate

$$
\|\mathrm{u}\|_{L^{\infty}(\Omega)} \leq \mathrm{k}\|\mathrm{Lu}\|_{L^{\mathrm{q}}(\Omega)}
$$

if $u$ is a solution of problem (1) with Lu in place of $f$, for some $\mathrm{q}<\mathrm{n}$, where $\mathrm{k}=\mathrm{k}(\lambda, \Omega, \mathrm{q})$.

The following theorem is a maximum principle for solutions of second order nondivergence form elliptic equations with discontinuous coefficients. Let us consider the operator

$$
\begin{gathered}
\mathrm{Lu}=\sum_{\mathrm{i}, \mathrm{j}=1}^{\mathrm{n}} \mathrm{a}_{\mathrm{ij}}(\mathrm{x})\left(\partial^{2} \mathrm{u} / \partial \mathrm{x}_{\mathrm{i}} \partial \mathrm{x}_{\mathrm{j}}\right), \text { in } \Omega \text { with } \\
\mathrm{a}_{\mathrm{ij}}(\mathrm{x}) \in \mathrm{L}^{\infty}(\Omega), \mathrm{a}_{\mathrm{ij}}(\mathrm{n})=\mathrm{a}_{\mathrm{ji}}(\mathrm{n}), \\
\sum_{\mathrm{i}-1}^{\mathrm{n}} \mathrm{a}_{\mathrm{iij}}(\mathrm{n})=1, \lambda|\xi|^{2} \leq \sum_{\mathrm{i}, \mathrm{j}=1}^{\mathrm{n}} \mathrm{a}_{\mathrm{ij}}(\mathrm{x}) \xi_{\mathrm{i}} \xi_{\mathrm{j}}
\end{gathered}
$$

a.e. in $\Omega$, for any $\xi \in \mathrm{R}^{\mathrm{n}}$. We prove the following

Theorem 3: There exists $\mathrm{q}<\mathrm{n}$ and $\mathrm{k}=\mathrm{k}(\lambda, \Omega$, q). Such that, under hypotheses (11) only, (10) holds for any

$$
\mathrm{u} \in \mathrm{W}^{2, \mathrm{n}}(\Omega) \cap \mathrm{C}^{0}(\bar{\Omega})
$$

Proof : Let $\left(\mathrm{a}_{\mathrm{ij}}^{\mathrm{d}}(\mathrm{x})\right)_{\mathrm{d}}$ be a sequence of $\mathrm{C}^{\infty}$ functions tending to $a_{i j}(x)$ in $L^{n q} /(n-q)$, for any $1 \leq I, j \leq n$. We note also that we can choose $\mathrm{a}_{\mathrm{ij}}^{\mathrm{d}}$ in such a way that for any of them (11) holds, with the same $\lambda$. We fix

$$
\begin{gathered}
\mathrm{u} \in \mathrm{W}^{2, \mathrm{n}}(\Omega) \cap \mathrm{C}^{0}(\bar{\Omega}),\left.\mathrm{u}\right|_{\partial \Omega}=0 \\
\text { set } \mathrm{L}_{\mathrm{d}} \mathrm{u}=\sum_{\mathrm{i}, \mathrm{j}=1}^{\mathrm{n}} \mathrm{a}_{\mathrm{ij}}^{\mathrm{d}}\left(\partial^{2} \mathrm{u} / \partial \mathrm{x}_{\mathrm{i}} \partial \mathrm{x}_{\mathrm{j}}\right)
\end{gathered}
$$

and note that by (10), 


$$
\|\mathrm{u}\|_{\mathrm{L}^{\infty}(\Omega)} \leq \mathrm{k}\left\|\mathrm{L}_{\mathrm{d}} \mathrm{u}\right\|_{\mathrm{L}^{\mathrm{q}}(\Omega)}
$$

With $\mathrm{k}=\mathrm{k}(\lambda, \Omega, \mathrm{q})$, independent on $\mathrm{d}$. We have, using Hőlder's inequality,

$$
\begin{aligned}
& \sum_{\mathrm{i}, \mathrm{j}=1}^{\mathrm{n}} \int_{\Omega}\left|\mathrm{a}_{\mathrm{ij}}^{\mathrm{d}}(\mathrm{x})-\mathrm{a}_{\mathrm{ij}}(\mathrm{x})\right|^{\mathrm{q}}\left|\frac{\partial^{2} \mathrm{u}}{\partial \mathrm{x}_{\mathrm{i}} \partial \mathrm{x}_{\mathrm{j}}}\right|^{\mathrm{q}} \mathrm{dx} \\
& \leq \sum_{\mathrm{i}, \mathrm{j}=1}^{\mathrm{n}}\left(\left.\int_{\Omega}\left|\frac{\partial^{2} \mathrm{u}}{\partial \mathrm{x}_{\mathrm{i}} \partial \mathrm{x}_{\mathrm{j}}}\right|^{\mathrm{n}} \mathrm{dx}\right|^{\mathrm{q} / \mathrm{n}} \mid\left(\int_{\Omega}\left|\mathrm{a}_{\mathrm{ij}}^{\mathrm{d}}-\mathrm{a}_{\mathrm{ij}}\right|^{\mathrm{nq} /(\mathrm{n}-\mathrm{q})} \mathrm{dx}\right)^{(\mathrm{n}-\mathrm{q}) / \mathrm{n}}\right.
\end{aligned}
$$

From (13) we deduce that $L_{d} u$ tends to $L u$ in $L^{q}(\Omega)$. Then, from (12) and (13), letting d go to infinity we obtain the theorem.

\section{DISCUSSION}

Now we consider a maximum principle in small domains. During the sixties, Alexandroff, Bakelman and Pucci introduced a method which we call the ABP method to prove the ABP estimate, Theorem 4 below. The ABP estimate is an L. bound for solutions of uniformly elliptic equations $\mathrm{Lu}=\mathrm{f}(\mathrm{x})$ written in nondivergence form and with measurable coefficients. It plays a key role in the regularity theory for fully nonlinear elliptic equations.

Let $\mathrm{L}$ denotes an operator of the form

$$
\mathrm{Lu}=\mathrm{a}_{\mathrm{ij}}(\mathrm{x}) \partial_{\mathrm{ij}} \mathrm{u}+\mathrm{b}_{\mathrm{i}(\mathrm{x})} \partial_{\mathrm{i}} \mathrm{u}+\mathrm{c}(\mathrm{x}) \mathrm{u},
$$

in a bounded domain $\Omega \subset \mathrm{R}^{\mathrm{n}}$. We assume that $\mathrm{L}$ is uniformly elliptic and has bounded measurable coefficients:

$$
\left(\sum \mathrm{b}_{\mathrm{i}}^{2}\right)^{1 / 2} \leq \mathrm{b} \text { and }|\mathrm{c}| \leq \overline{\mathrm{b}} \text { in } \Omega
$$

for some nonnegative constants $\mathrm{b}$ and $\overline{\mathrm{b}}$.

The following theorem, called ABP estimate, was proved by Alexandroff, Bakelman and Pucci in the sixties. It is an essential tool in the regularity theory for fully nonlinear equations. In its statement, $\mathrm{W}_{\mathrm{Loc}}^{2, \mathrm{n}}(\Omega)$ denotes the Sobolev space of functions that, together with their second derivatives, belong to $\mathrm{L}_{\mathrm{Loc}}^{\mathrm{n}}(\Omega)$.

Theorem 4: Assume that $\Omega \subset \mathrm{R}^{\mathrm{n}}$ is a bounded domain and that $\mathrm{c} \leq 0$ in $\Omega$. Let

$$
\mathrm{u} \in \mathrm{W}_{\mathrm{Loc}}^{2, \mathrm{n}}(\Omega) \cap \mathrm{C}(\bar{\Omega})
$$

satisfy
$\mathrm{Lu} \geq \mathrm{f}$ in $\Omega$ and $\mathrm{u} \leq 0$ on $\partial \Omega$, where $\mathrm{f} \in \mathrm{L}^{\mathrm{n}}(\Omega)$. Then,

$$
\sup _{\Omega} \leq \operatorname{Cdiam}(\Omega)\|\mathrm{f}\|_{L^{\mathrm{n}}\left(\Gamma^{\mathrm{u}^{+}}\right)}
$$

where

$$
\Gamma^{\mathrm{u}+}=\{\mathrm{x} \in \Omega: \mathrm{u}(\mathrm{x})>0
$$

and

$$
\left.\mathrm{u}^{+}(\mathrm{y}) \leq \mathrm{u}(\mathrm{x})+\nabla \mathrm{u}(\mathrm{x}) \cdot(\mathrm{y}-\mathrm{x}) \text { for all } \mathrm{y} \in \bar{\Omega}\right\}
$$

is the upper contact set of $\mathrm{u}+:=\max (\mathrm{u}, 0)$ and $\mathrm{C}$ is a constant depending only on $\mathrm{n}, \lambda$ and b.diam $(\Omega)$.

An improved version of the ABP estimate, where the factor diam $(\Omega)$ is replaced by $|\Omega|^{1 / n}$, was found by the Cabre ${ }^{[14]}$.

Proof: Let $\mathrm{M}:=\sup _{\Omega}=\mathrm{u}\left(\mathrm{x}_{0}\right)>0$ be achieved at $\mathrm{x}_{0} \in \Omega$ recall that $\mathrm{u} \leq 0$ on $\partial \Omega$. Let $\mathrm{d}=\operatorname{diam}(\Omega)$. We work with the function $\mathrm{v}:=-\mathrm{u}+$. Hence,

$$
-\mathrm{M}:=\inf _{\Omega} \mathrm{v}=\mathrm{v}\left(\mathrm{x}_{0}\right), \mathrm{v} \leq 0 \text { in } \Omega
$$

and $\mathrm{v}=0$ on $\partial \Omega$. Consider the lower contact set $\Gamma_{\mathrm{v}}$ of $\mathrm{v}$, defined by

$$
\Gamma_{\mathrm{v}}=\{\mathrm{x} \in \Omega: \mathrm{v}(\mathrm{y}) \geq \mathrm{v}(\mathrm{x})+\nabla \mathrm{v}(\mathrm{x}) \cdot(\mathrm{y}-\mathrm{x})\}
$$

for all $\mathrm{y} \in \bar{\Omega}$.

Note that in this set we have $v<0$ and hence $u>0$. Let $\mathrm{A}(\mathrm{x}):=\left[\mathrm{a}_{\mathrm{ij}}(\mathrm{x})\right]$ and note that

$$
\begin{aligned}
& \operatorname{tr}(\mathrm{A}(\mathrm{x}) \mathrm{D} \mathrm{v})=\operatorname{aij}(\mathrm{x}) \partial_{\mathrm{ij}} \mathrm{u} \\
& =-\mathrm{Lu}+\mathrm{c}(\mathrm{x}) \mathrm{u} £-\mathrm{Lu} £-\mathrm{f}(\mathrm{x}) \text { in } \mathrm{Gv}
\end{aligned}
$$

since $c \leq 0$. Now the statement that replaces

$$
\mathrm{B}_{1} \subset \nabla \mathrm{v}\left(\Gamma_{\mathrm{v}}\right)
$$

is $\mathrm{B}_{\mathrm{M} / \mathrm{d} C} \nabla \mathrm{v}\left(\Gamma_{\mathrm{v}}\right)$. This is proved, as before, using the Legendre transform

$$
\min _{\mathrm{y} \in \bar{\Omega}}\{\mathrm{v}(\mathrm{y})-\mathrm{p} \cdot \mathrm{y}\}=\mathrm{v}(\mathrm{x})-\mathrm{p} \cdot \mathrm{x}
$$

of $\mathrm{v}$ and checking that the minimum is achieved at an interior point $\mathrm{x} \in \Omega$ and not at the boundary $\partial \Omega$. Indeed, for every $\mathrm{y} \in \partial \Omega$. We have that

$$
v(y) \cdot p y=-p y>
$$




$$
-\mathrm{M}-\mathrm{p} \cdot \mathrm{x}_{0}=\mathrm{v}\left(\mathrm{x}_{0}\right)-0 \mathrm{p} \cdot \mathrm{x}_{0}
$$

since $\left|\mathrm{y}-\mathrm{x}_{0} \leq \mathrm{d}\right|$ and we took $\mathrm{p}$ such that $|\mathrm{p}|<$ $\mathrm{M} / \mathrm{d}$.Using the area formula we deduce that

$$
\mathrm{c}(\mathrm{n})(\mathrm{M} / \mathrm{d})^{\mathrm{n}}=\left|\mathrm{B}_{\mathrm{M} / \mathrm{d}}\right| \leq\left|\nabla \mathrm{v}\left(\Gamma_{\mathrm{v}}\right)\right| \leq \int_{\Gamma_{\mathrm{v}}} \operatorname{det}^{2} \mathrm{v}(\mathrm{x}) \mathrm{dx}
$$

For $\mathrm{x} \in \Gamma_{\mathrm{v}} \mathrm{x}$, we now bound det $\mathrm{D}^{2}$ as follows (16) leads to

$$
\begin{gathered}
\operatorname{det} \mathrm{D}^{2} \mathrm{v}(\mathrm{x})=\frac{1}{\operatorname{det} \mathrm{A}(\mathrm{x})} \operatorname{det} \mathrm{A}(\mathrm{x}) \mathrm{D}^{2} \mathrm{v}(\mathrm{x}) \\
\leq \lambda^{-\mathrm{n}} \operatorname{det}\left(\mathrm{A}(\mathrm{x}) \mathrm{D}^{2} \mathrm{v}(\mathrm{x})\right) \leq \lambda^{\mathrm{n}} \\
\left\{\frac{\operatorname{tr}\left(\mathrm{A}(\mathrm{x}) \mathrm{D}^{2} \mathrm{v}(\mathrm{x})\right)}{\mathrm{n}}\right\}^{\mathrm{n}}(\mathrm{n} \lambda)^{-\mathrm{n}}(-\mathrm{f}(\mathrm{x}))^{\mathrm{n}} \leq \mathrm{C}|\mathrm{f}(\mathrm{x})|^{\mathrm{n}} \\
\left.\mathrm{D}^{2} \mathrm{v}(\mathrm{x})\right) \leq \lambda^{-\mathrm{n}}\left\{\frac{\operatorname{tr}\left(\mathrm{A}(\mathrm{x}) \mathrm{D}^{2} \mathrm{v}(\mathrm{x})\right)}{\mathrm{n}}\right\}^{\mathrm{n}} \\
\leq(\mathrm{n} \lambda)^{-\mathrm{n}}(-\mathrm{f}(\mathrm{x}))^{\mathrm{n}} \leq \mathrm{C}|\mathrm{f}(\mathrm{x})|^{\mathrm{n}}
\end{gathered}
$$

We deduce the ABP estimate,

$$
\sup _{\Omega} \mathrm{u}=\mathrm{Cd}\|\mathrm{f}\|_{\mathrm{L}^{\mathrm{n}}(\Omega)}
$$

Next, we introduce a standard terminology in bounded domains.

Definition : We say that the maximum principle holds for the operator $L$ in $\Omega$ if, whenever

$$
\mathrm{u} \in \mathrm{W}_{\mathrm{loc}}^{2, \mathrm{n}}(\Omega) \cap \mathrm{C}(\bar{\Omega})
$$

$\mathrm{Lu} \geq 0$ in $\Omega$ and $\mathrm{u} \leq 0$ on $\partial \Omega$, then necessarily $\mathrm{u} \leq 0$ in $\Omega$. The following corollary is an immediate consequence of Theorem 4 .

Corollary : Let $\Omega$, be a bounded domain of $\mathrm{R}^{\mathrm{n}}$. If $\mathrm{c} \leq 0$ in $\Omega$, then the maximum principle holds for $\mathrm{L}$ in $\Omega$. The condition $\mathrm{c} \leq 0$ in $\Omega$ is, however, too restrictive for some applications. The following maximum principle in domains of small measure does not make any assumption on the sign of $\mathrm{c}$ and it will be very useful.

Proposition : Assume that $\Omega$ is a bounded domain of $\mathrm{R}^{\mathrm{n}}$. Then, there exists a constant $\delta>0$ depending only on $\mathrm{n}, \lambda, \mathrm{b}, \overline{\mathrm{b}}$ and diam $(\Omega)$, such that the maximum principle holds for $\mathrm{L}$ in $\Omega$ if the measure of satisfies $|u| \leq \delta$.

This proposition is a consequence of the $\mathrm{ABP}$ estimate that was first noted by Bakelman, later by Varadhan and then extensively used by Berestycki and Nirenberg. Similar maximum principles in small

domains can be obtained also for divergence form operators L, where

$$
\mathrm{Lu}:=\partial_{\mathrm{i}}\left(\mathrm{a}_{\mathrm{ij}}(\mathrm{x}) \partial_{\mathrm{j}} \mathrm{u}\right)=\mathrm{f}(\mathrm{x})
$$

For this, kone uses techniques from the variational theory which are clearly presented by Brezis ${ }^{[13]}$.

Proof: Let u satisfy $\operatorname{Lu} \geq 0$ in $\Omega$ and $u \leq 0$ on $\partial \Omega$. Let $d=$ $\operatorname{diam}(\Omega)$ and $\mathrm{c}=\mathrm{c}^{+}-\mathrm{c}^{-}$, where $\mathrm{c}^{+}=\max (\mathrm{c}, 0)$ and $\mathrm{c}^{-}=$ $\max (-\mathrm{c}, 0)$. Consider the

$$
\mathrm{L}_{0}=\mathrm{a}_{\mathrm{ij}} \partial_{\mathrm{ij}}+\mathrm{b}_{\mathrm{i}}(\mathrm{x}) \partial_{\mathrm{i}}
$$

Writing $\mathrm{Lu} \geq 0$ in the form

$$
\left(\mathrm{L}_{0}-\mathrm{c}^{-}\right) \mathrm{u} \geq-\mathrm{c}^{+} \mathrm{u} \geq-\mathrm{c}^{+} \mathrm{u}^{+}
$$

we may apply the ABP estimate to the operator $\mathrm{L}_{0}-\mathrm{c}$ and obtain

$$
\begin{aligned}
& \sup _{\Omega} \mathrm{u} \leq \mathrm{C}(\mathrm{n}, \lambda, \mathrm{b}, \mathrm{d})\left\|\mathrm{c}^{+} \mathrm{u}^{+}\right\|_{\mathrm{L}^{\mathrm{n}}(\Omega)} \\
& \leq \mathrm{C}(\mathrm{n}, \lambda, \mathrm{b}, \overline{\mathrm{b}}, \mathrm{d})|\Omega|^{1 / \mathrm{n}} \sup _{\Omega} \mathrm{u}^{+} \\
& \quad \text { if } \mathrm{C}(\mathrm{n}, \lambda, \mathrm{b}, \overline{\mathrm{b}}, \mathrm{d})|\Omega|^{1 / \mathrm{n}} \leq 1 / 2
\end{aligned}
$$

we conclude that $\mathrm{u} \leq 0$ in $\Omega$.

\section{REMARKS}

We note that Theorem 3 holds for any

$$
u \in W^{2, \uparrow}(\Omega) \cap C^{0}(\bar{\Omega}),\left.\quad u\right|_{\partial \Omega}=0
$$

with

$$
\mathrm{q}<\mathrm{p} \leq \mathrm{n}
$$

Using Theorem 2, in ${ }^{[5]}$ the existence of a function $\alpha(\lambda)$ is proved such that (10) holds for 


$$
\alpha(\lambda)<\mathrm{q} \leq \mathrm{n} \text { and } \mathrm{n}-\alpha(\lambda)>\mathrm{k} \lambda^{(5 \mathrm{n}-1) /(\mathrm{n}-1)}
$$

for some positive constant $\mathrm{k}$ independent on $\lambda \in(0,1 / \mathrm{n}]$

From Theorem 3 and remarks (20) and (21) we deduce the following remark concerning the estimates a priori for the displacement of a structure subjected to concentrated loads.

Consider the possibility of bounds like (10) when the coefficients are discontinuous and $\mathrm{f}(\mathrm{p})$, the known term, allows singularities like

$$
1 /[\mathrm{d}(\mathrm{P}, \overline{\mathrm{P}})]^{\sigma}, \sigma \geq 1, \overline{\mathrm{P}} \in \bar{\Omega}
$$

Using Theorem 3 we note that we can obtain $\mathrm{L}^{\infty}$ bounds for the displacements in terms of $\mathrm{L}^{\mathrm{q}}$ norms, for some $\mathrm{q}<\mathrm{n}-\sigma$, of the loads. We obtain these bounds for some $\sigma \geq 1$ and for displacements belonging to

for some

$$
\mathrm{u} \in \mathrm{W}^{2, \uparrow}(\Omega) \cap \mathrm{C}^{0}(\bar{\Omega})
$$

$$
\mathrm{q}<\mathrm{p}<\mathrm{n}-\sigma
$$

By remark (22) we note that the bounds worsen if the draught tends to zero and we can estimate how $\mathrm{q}$ tends to $n-\sigma$.

\section{CONCLUSION}

This paper provides a larger picture of some techniques and results for maximum principles in elliptic PDEs in an informative way. We focus mainly on nondivergence form with discontinuous or measurable coefficients.

\section{REFERENCES}

1. Alexandrov, A.D., 1997. Majorizations of Solutions of Second Order Linear Equations, Am. Math. Soc. Transl., 68: 120-144.

2. Cristian, P.D., 2006. Anote on Maximum Principles for Equations of Nondivergence Form, Int. J. Math. and Comp. Sci., 21: 191-200.
3. Fabes, E.B. and D.W. Strook, 1984. The $\mathrm{L}^{\mathrm{p}}$ Integrability of Green Function and Fundamental Solutions for Ellipic and Parabolic Equations. Duke Math. J., 51: 997-1016.

4. Franciosi, M. and G. Moscariello, 1985. Higher Integrability Results. Manuscripta Math., 52: 151-171.

5. Franciosi, M. and G. Moscariello, 2001. A Note on the Maximum Principle for Second Order Nonvariational Linear Elliptic Equations. Ricerche Math., 66: 234-246.

6. Franciosi,V. Fondamenti di Scienza Delle Contruzioni, Liguori, Napoli.

7. Manselli, P., 1979. A Variational Approach to A Priori Bound for Elliptic Equations. Drivate Parziali, Bologna, Le Matematiche, 34: 39-56.

8. Pucci, C. and G. Talenti, 1976. Elliptic Second Order Partial Equations with Measurable Coefficients and Approximating Integral Equations. Adv. Math., 19: 48-105.

9. Sbordone, C., 1985. Rearrangments of Functions and Reverse Hölder Inequalities. Colloque E. de Giorgi, Paris, Res. Notes in Math. Pitman, Boston.

10. Talenti, G., 1981. Some Estimates of Solutions to Monge-Ampere Type Equations in Dimension Two, Ann. Scuola Norm. Sup. Pisa Cl. Sci., 3: 185-230.

11. Stein, E.M. and G. Weiss, 1971. Introduction to Fourier Analysis on Euclidean Spaces, Princeton University Press, Princeton, NJ.

12. Berestycki, H. and L. Nirenberg, 1991. On the Method of Moving Planes and the Sliding Method. Bull. Soc. Brasil Mat., (N.S.) 22: 137.

13. Brezis, H., 1999. Symmetry in Nonlinear PDEs, Differential Equations: La Pietra 1996 (Florence), 112, Proc. Sympos. Pure Math., 65, Am. Math. Soc., Providence, RI.

14. Cabre, X., 1995. On the Alexandroff-BakelmanPucci Estimate and the Reversed Holder Inequality for Solutions of Elliptic and Parabolic Equations. Comm. Pure Applied Math., 48: 539-570. 